\title{
Increasing the efficiency of split type air conditioners/heat pumps by using ventilating exhaust air
}

\author{
Wojciech Cepiński ${ }^{1, *}$, and Pawet Szałański ${ }^{1}$ \\ ${ }^{1}$ Department of Air Conditioning, Heating, Gas Engineering and Air Protection, Faculty \\ of Environmental Engineering, Wrocław University of Science and Technology, ul. C.K. Norwida \\ 4/6, 50-373 Wrocław, Poland
}

\begin{abstract}
The article presents the possibility of using exhaust air from ventilation system to increase the efficiency (SCOP, COP, SEER and EER) of commonly used air conditioners with the function of a heat pump. These types of devices are very popular both in residential and in public buildings. The topic discussed in the article is very important, because the widespread increase of the energy efficiency of these devices significantly influences national electricity consumption. The possibility of increasing their efficiency by directing the exhaust air from the ventilation system to the heat exchanger of the air conditioner outdoor unit has been analysed. It has been shown that the use of the simple design solution described in the article allows for a significant increase of the efficiency of these devices (seasonal efficiency even up to $35 \%$ at $100 \%$ share of exhaust air), reducing the energy consumption and increasing their capacity and operation range. By increasing the share of exhaust air it is possible to ensure year-round operation of the device and even $100 \%$ coverage of heat demand.
\end{abstract}

\section{Introduction}

Nowadays it is necessary to face the dynamically growing energy demand. This is a very important task for mankind in the face of a dynamic increase of the number of humanity accompanied by the increasing amount of energy consumed by each of us, resulting from the desire to use energy-consuming comforts such as being online, using individual transport, air conditioning in flats and houses. It is our duty, not only as researchers, but also as people to constantly search for solutions that limit the consumption of the dynamically shrinking natural resources of our planet. It is necessary to increase public awareness of the negative impact of increasing energy consumption on the environment in which we live and our descendants will live. This should be associated with the widespread development of a low-energy lifestyle. However, it is a prerequisite to create technology that uses energy as efficiently as possible.

\footnotetext{
* Corresponding author: wojciech.cepinski@pwr.edu.pl, ORCID: 0000-0003-4294-0431, Paweł Szałański ORCID: 0000-0001-9263-3486
} 
The EU Directive [1] imposes on individual member states an obligation to reduce primary energy consumption. In the case of energy consumed by buildings, this goal can only be achieved by reducing the energy need for heating or by improving the efficiency and energy efficiency of appliances. The more common the technology is, the more important it is to increase its efficiency. The topic of estimating energy need for heating is discussed in the [2].

Due to the increase in the wealth of the societies of many countries in Europe and the reduction of the costs of various types of technologies, access to this type of goods is becoming more and more common. On the example of Poland, air-conditioning technology, which until a dozen years ago was an indicator of luxury, is now widely available and at prices similar to computers, TV sets or mobile phones. Today, room cooling is no longer a luxury good. Today, room cooling is no longer a luxury good. In Poland, 20\% of the air conditioners market in 2015 was residential construction [3]. Currently, the devices of this type have the ability to reverse the cooling circuit and operate in the heat pump mode. Therefore, it is very popular to use them also in the function of room heating. That is why these devices often operate in full-year mode, which increases the impact of their efficiency on the environment.

The market for these devices has been very receptive in recent years and it can be said that Poland has been flooded with them in recent years. The Polish market of air conditioners is estimated at over PLN 1 billion annually [3]. At the price of a branded set of approx. 3-4 kW for a room of approx. $30 \mathrm{~m}^{3}$ oscillating around 3500-5000 PLN with installation [3], it may result in 200,000-280,000 devices of this type installed annually. The forecasted popularity of air conditioners in Poland is also the growing market of new flats, as the use of these devices is already very popular not only in office buildings, but also in flats and houses [4]. Popularity of these devices in Europe is considered in [5].

Due to the popularity of these devices, it is imperative to improve their energy efficiency. In [6], an attempt to optimize the seasonal efficiency of air-to-air heat pumps is presented. In [7], the economics of using an air-to-air heat pump as an alternative to a gas-fired boiler was analyzed. The paper [8] discusses the rules for optimal heat pump sizing in a fixed site. The proper sizing of heat pumps should be based on simulations of their efficiency, the subject of which was considered in [9].

The aim of this article is to present a very simple and often cost-free solution, enabling a significant increase in the energy efficiency of cooling and heating air conditioners, using heat usually lost in ventilation systems. Heat recovery from ventilation systems requires other solutions than, for example, heat recovery from hot flue gases discussed in [10]. Popularization of the proposed solution may have a significant impact on the reduction of the national energy demand and a significant reduction in the emission of coal combustion products to the atmosphere due to the supply of electricity to these devices in Poland, mainly from coal.

\subsection{Characteristics of the analysed devices}

Split air conditioners consist of five basic components: compressor, expansion valve, evaporator, condenser and connecting piping. Such a system is filled with refrigerant with appropriate thermodynamic properties. When operating in cooling mode, the unit receives heat by means of a evaporator located in the cooled room. The properties and parameters of the refrigerant are so selected that when entering the evaporator in the form of liquid, it receives heat from the air around evaporator and evaporates as a result of the associated increase in its temperature. The refrigerant is then transported by a compressor to a condenser located outside the room. There, the refrigerant transfers heat to the air around condenser, as a result of which it cools down and as a result its condensation takes place. 
Air conditioners with heat pump function have the ability to reverse the cooling circuit and as a result heat the room. After reversing the circuit, the unit becomes an air-to-air heat pump. The exchanger in the room becomes a condenser, and the exchanger located outside the room becomes a evaporator. As a result, the heat received from the surrounding evaporator is transported to the condenser and then transferred to the air in the room. In this situation, the air surrounding the condenser in the room is the upper source of the heat pump and the air surrounding the evaporator located outside the room is the lower source of the heat pump.

The main feature of these devices, operating in both heating and cooling mode, is the transfer of heat from a lower temperature environment to a higher temperature environment. The main feature of these devices, operating in both heating and cooling mode, is the transfer of heat from a lower temperature environment to a higher temperature environment. One of the main factors influencing the efficiency and energy efficiency of these devices is the temperature difference that the device has to overcome, that is between the temperature of the medium from which the heat is taken and the medium to which the heat is transferred. Improper heat dissipation in cooling mode and too low ambient air temperature in heating mode can significantly reduce the efficiency of the evaporator. The problem of high operating costs due to poor heat recovery is highlighted in [4].

\subsection{Coefficients of performance COP, SCOP, EER, SEER}

The efficiency of a heat pump under certain operating conditions (e.g. outdoor and indoor air parameters) is determined by the COP (Coefficient Of Performance). It is equal to the ratio of the heating capacity of the device to the electrical power input of the device equation (1).

The seasonal efficiency of a heat pump under certain climatic conditions is determined by the SCOP (Seasonal Coefficient Of Performance). It is equal to the ratio of the annual heating demand supplied by the device to the seasonal electrical energy consumption of the device - equation (2).

The efficiency of a cooling unit under certain operating conditions (e.g. outdoor and indoor air parameters) is determined by the EER (Energy Efficiency Ratio). It is equal to the ratio of the cooling capacity of the device to the electrical power input of the device - equation (3).

The seasonal efficiency of a cooling unit under certain climatic conditions is determined by the SEER (Seasonal Energy Efficiency Ratio). It is equal to the ratio of the seasonal cooling demand supplied by the device to the seasonal electrical energy consumption of the device - equation (4).

$$
C O P=\frac{P_{H}}{P_{e l H}} \quad \text { (1) } \quad S C O P=\frac{Q_{H}}{Q_{H E}} \quad \text { (2) } \quad E E R=\frac{P_{C}}{P_{e l C}} \quad \text { (3) } \quad S E E R=\frac{Q_{C}}{Q_{C E}}
$$

where:

$P_{H}$ and $P_{C}$ - heating and cooling capacity output at a specific conditions, $\mathrm{kW}$

$P_{e l H}$ and $P_{e l C}$ - power input at a specific conditions in a heating and cooling mode, $\mathrm{kW}$

$Q_{H}$ and $Q_{C}$ - annual heating and cooling demand supplied by the device, $\mathrm{kWh}$

$Q_{H E}$ and $Q_{C E}$ - annual electricity consumption for heating and cooling, $\mathrm{kWh}$.

\section{Description and analysis of the proposed solution}

The simplest way to increase energy efficiency is to ensure the lowest possible temperature difference between these media. The temperature in rooms usually cannot be changed due to the principle of using the device, which is to provide adequate thermal comfort. 
Therefore, it is only possible to ensure the most appropriate air temperature around the outdoor unit as close as possible to the room air temperature. The typical location of an outdoor unit of an air conditioner is the outdoor environment. The outdoor units are usually mounted on the external walls of buildings, on roofs or at ground level near the building. Much less common solution to increase energy efficiency is to install them in spaces with a higher air temperature, for example in indoor spaces such as unheated underground garages. There are also works showing the possibility of increasing energy efficiency by washing the exchanger of the outdoor unit with heated or cooled air from the ground exchanger $[11,12]$. These solutions are effective, but can be used in specific circumstances and require the use of additional components and devices.

In contrast, the solution proposed in this article may become much more common as it does not require significant additional expenses. Its idea is presented on figure 1.

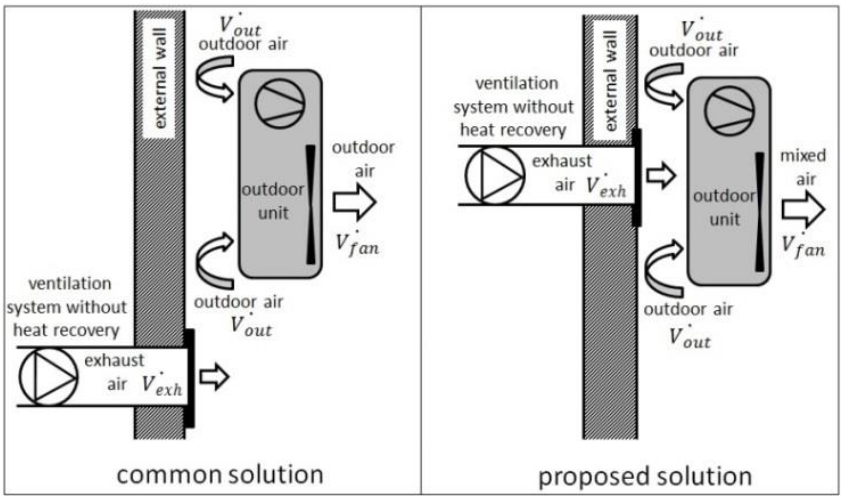

Fig. 1. Diagram with an air conditioner that operates only in outdoor air (common solution) and in a mixture of outdoor and exhaust air (proposed solution).

Typical solutions do not pay attention to the location of the air conditioning outdoor unit in relation to the air exhaust of the ventilation system. The air flow through the outdoor unit is a characteristic parameter and we have no influence on it. We can only have an influence on the temperature of this stream. Appropriate placement of the air exhaust enables directing the extracted air from rooms to the exchanger of the outdoor unit. As a result, the exchanger will be surrounded by a mixture of extract air and external air. During the heating period, the air from the room has a higher temperature than the outdoor air, so that the temperature of the mixture will be higher the higher the percentage of exhaust air will be. On the contrary, during the cooling period, the indoor air in the cooled room has a temperature lower than the outdoor air temperature. With the proposed solution, in the heating period the exchanger of the outdoor unit operates in the environment of warmer air, and in the cooling period colder. An additional advantage of the solution is the possibility of using air exhausted from rooms polluted by smell, e.g. from toilets, garages or other places where it is not possible to apply heat recovery, if this air is not destructive to the heat exchanger. The above enables the use of almost all thermodynamic advantages of the exhaust air because of its temperature and relative humidity, which increases the capacity of the device.

\subsection{Comparative analysis of air conditioner operation}

The assumptions and results of the analysis (figure 2-3) of the impact of the proposed solution on the parameters of an exemplary air conditioner are presented below.

For a typical and proposed solution, the following were compared: 
- the dependence of the heating power of the device on the outdoor air temperature,

- the dependence of the energy efficiency coefficient of the device on the outdoor air temperature in the heating mode,

- the dependence of the energy efficiency coefficient of the device on the outdoor air temperature in the heating mode,

- the operating range of the device in heating mode,

- dependence of the cooling capacity of the unit on the outdoor air temperature,

- dependence of the coefficient of energy efficiency of the unit on the temperature of the outdoor air in cooling mode,

- the operating range of the unit in cooling mode.

The results of the analysis were presented for different values of the percentage of exhaust air in the air flow through the exchanger of the outdoor unit, defined as:

$$
A R R=\frac{V_{\text {exh }}^{\cdot}}{V_{\text {fan }}^{\dot{*}}}=\frac{V_{\text {exh }}^{\cdot}}{V_{\text {exh }}^{\cdot}+V_{\text {out }}^{\cdot}}
$$

where:

$V_{\text {exh }}^{\cdot}$ - exhaust air flow from the ventilation system, $\mathrm{m}^{3} / \mathrm{h}$

$V_{\text {out }}$ - the outdoor air flow through the fan of the outdoor unit of the air conditioner, $\mathrm{m}^{3} / \mathrm{h}$

$V_{\text {fan }}^{\cdot}$ - the total flow of air flowing through the heat exchanger of the outdoor unit of the air conditioner, $\mathrm{m}^{3} / \mathrm{h}$.

The analysis was carried out with the following assumptions:

- in a typical solution, the outdoor unit operates only in the outdoor air and COP, EER, $P_{H}, P_{C}$ are the functions of outdoor temperature $T_{e}$ (in this case $T_{e}=T_{o u}$ ),

- in the proposed solution, the outdoor unit operates on a ideally mixed outdoor and exhaust air and COP, EER, $P_{H}, P_{C}$ are the functions of temperature of mixed outdoor and exhaust air surrounding the outdoor unit $T_{o u}$,

- no heat recovery in the ventilation system,

- constant exhaust air temperature during the heating and cooling period of $20^{\circ} \mathrm{C}$,

- for estimation of SCOP and SEER climatic data for the city of Wroclaw [13] in south-western Poland was considered using bin method (average duration of particular external temperature ranges was used),

- constant value of the total fan-flow of the outdoor unit of the air conditioner $V_{f a n}$, but different for heating and cooling mode,

- the air conditioner has been designed to cover the capacity needed for cooling during the cooling period,

- an exemplary profile of heat load of a building/room depending on heat loss by transmission and ventilation at a given outdoor temperature during the heating period, and depending on internal and solar heat gains, heat gains by transmission and ventilation at a given outdoor temperature in the cooling period,

- the heat gains from solar radiation in cooling mode depend linearly on the outdoor temperature [14],

- the device operates in ON/OFF mode with full power, adjusting its operating time to the needs,

- heating season at outdoor temperatures equal to or lower than $12^{\circ} \mathrm{C}$,

- cooling season with outdoor temperatures equal to or lower than $20^{\circ} \mathrm{C}$,

- the device does not operate at an outdoor temperature in the range of $12^{\circ} \mathrm{C}$ to $20^{\circ} \mathrm{C}$,

- the defrosting process will take place below an air temperature of $5^{\circ} \mathrm{C}$, 
- the additional energy consumption for defrosting the evaporator in heating mode is not included in the calculations.
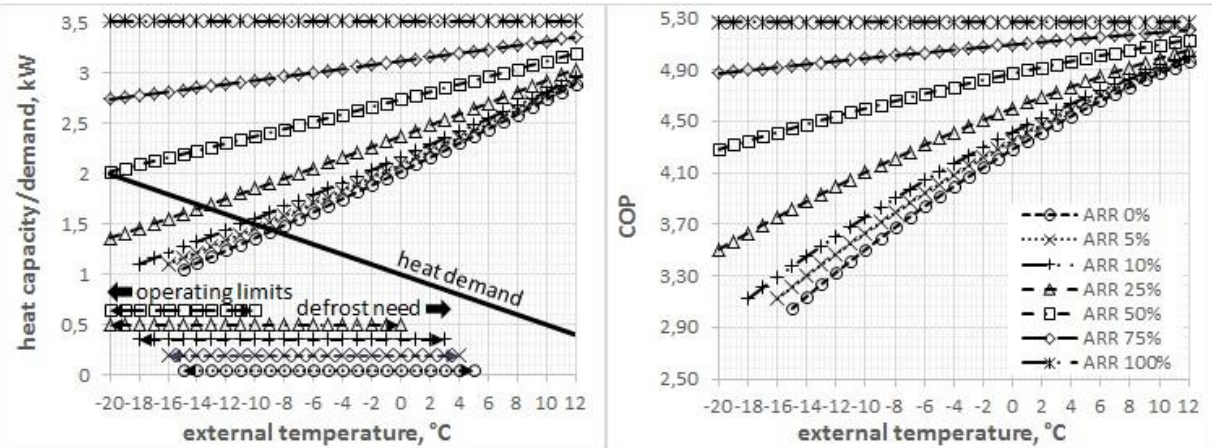

Fig. 2. Heating capacity and COP coefficient as the function of outdoor temperature.
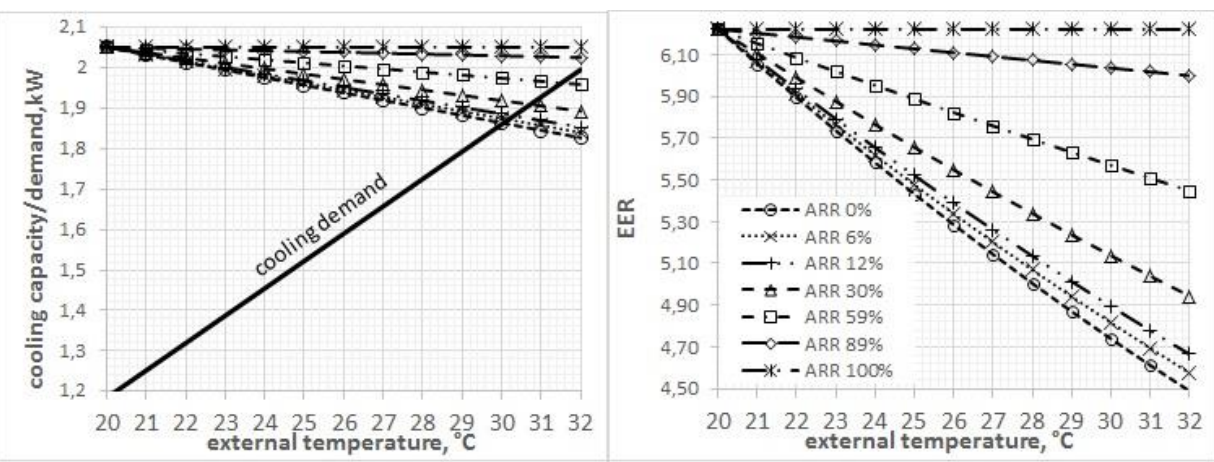

Fig. 3. Cooling capacity and EER coefficient as the function of outdoor temperature.

The following equations were used to determine the SCOP, without consideration of the auxiliary heater - equation (6) and considering auxiliary heater - equation (7). Analogical equations were used to determine SEER.

$$
\begin{array}{r}
S C O P=\frac{\sum_{j=1}^{n} h_{j} \cdot p l_{j}\left(T_{e j}\right) \cdot \operatorname{COP}_{j}\left(T_{\text {ouj }}\right) \cdot \min \left(1 ; \frac{Q_{H d j}\left(T_{e j}\right)}{P_{H j}\left(T_{o u j}\right)}\right)}{\sum_{j=1}^{n} h_{j} \cdot p l_{j}\left(T_{e j}\right) \cdot \min \left(1 ; \frac{Q_{H d j}\left(T_{e j}\right)}{P_{H j}\left(T_{o u j}\right)}\right)} \\
\operatorname{SCOP}=\frac{\sum_{j=1}^{n} h_{j} \cdot p l_{j}\left(T_{e j}\right) \cdot \min \left(1 ; \frac{Q_{H d j}\left(T_{e j}\right)}{P_{H j}\left(T_{o u j}\right)}\right) \cdot\left(1+\left(\operatorname{COP}_{j}\left(T_{\text {ouj }}\right)-1\right) \cdot \max \left(1 ; \frac{P_{H j}\left(T_{o u j}\right)}{Q_{H d j}\left(T_{e j}\right)}\right)\right)}{\sum_{j=1}^{n} h_{j} \cdot p l_{j}\left(T_{e j}\right) \cdot \min \left(1 ; \frac{Q_{H d j}\left(T_{e j}\right)}{P_{H j}\left(T_{o u j}\right)}\right)}
\end{array}
$$

where:

$h_{j}$ - bin hours - hours per season for which an outdoor temperature interval occurs,

$Q_{H d}$ - heat demand of the building/room, $\mathrm{kW}$

$T_{o u}$ - temperature of air entering the outdoor unit, $T_{o u}=A R R \cdot T_{i}+(1-A R R) \cdot T_{e},{ }^{\circ} \mathrm{C}$

$p l$ - part load coefficient, $p l=\frac{T_{i}-T_{e}}{T_{i}-T_{e d}}$

$T_{i}$ and $T_{e}$ - indoor and outdoor air temperature, ${ }^{\circ} \mathrm{C}$

$T_{e d}$ - outdoor air temperature at design conditions, ${ }^{\circ} \mathrm{C}$. 


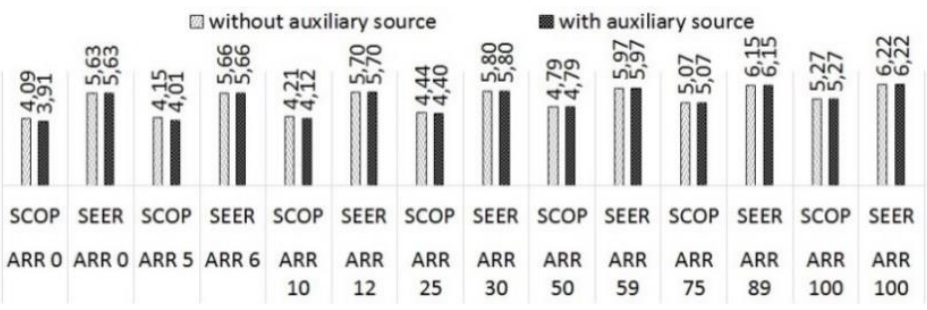

Fig. 4. SCOP and SEER in the function of ARR.

\subsection{Conclusions}

The results of the analysis (figure 2-4) indicate that the application of the proposed solution:

- increases the coefficients of performance in the heating mode COP (e.g. at $T_{e}=-20^{\circ} \mathrm{C}$ from $38 \%$ to $108 \%$ for ARR25 and ARR 100 respectively) and in the cooling mode EER (e.g. at $T_{e}=30^{\circ} \mathrm{C}$ from $9 \%$ to $32 \%$ for ARR30 and ARR100 respectively) at particular outdoor air temperatures,

- increases the seasonal coefficients of performance the SCOP and SEER devices (respectively even up to $35 \%$ and $11 \%$ at $100 \%$ share of exhaust air),

- may reduce investment costs for heating by enabling the use of a device with a lower nominal capacity, because as the temperature of mixed air increases (depending on the ratio of ARR), the heating capacity of the device increases - such a device will operate with a higher use of installed capacity,

- increases the temperature and power operating range of the air conditioner in heating mode (with a typical solution, the analysed exemplary device switches off below $15^{\circ} \mathrm{C}$ ), which may eliminate the need for an additional source of heat and become a monovalent system - in the considered case, for ARR equal to or greater than $25 \%$, the device can operate for the entire heating period, and for AAR equal to or greater than $50 \%$, it allows to eliminate the need for an additional source of heat,

- reduces the operating time of the unit in heating mode, where defrosting of the evaporator is needed - considering the high frequency of external temperatures at which defrosting is required, therefore by postponing this necessity by several degrees Celsius an even greater increase in seasonal efficiency of the heat pump is expected than the presented analysis (defrosting can reduce heat pump efficiency in the heating period by up to $10 \%$ ),

- allows to defrost the evaporator with warm air, which can also reduce the energy demand for this process, so even greater savings can be expected than presented in the analysis,

- may reduce investment costs for cooling by enabling the use of a device with a lower nominal capacity, because as the temperature of mixed air decreases (depending on the ratio of ARR), the cooling capacity of the device increases - such a device will operate with a higher use of installed capacity,

- increases the operating range of the unit in cooling mode,

- by increasing the capacity of the unit at particular outdoor temperatures, the total operating time in the season is reduced,

- reduces the operating time of the unit, which, due to the compressor's lifetime, can result in a few additional operating seasons,

In the case of using in the proposed way the air exhausted from the ventilation system with heat recovery, the effect will be much smaller, because the temperature of this air will 
be lower. The effect of the proposed solution will be lower the higher the efficiency of heat recovery is.

\section{Summary}

The presented analysis shows that the proposed solution, recommended for use in new and existing installations, may contribute to the improvement of seasonal efficiency of the device in both heating and cooling mode. Depending on the available exhaust air flow from the ventilation system, it can give significant savings and allows to reduce the primary energy consumption for the purpose of controlling the microclimate of rooms in an environmentally friendly way. This is particularly important in the climatic zone to which Poland belongs, because for these purposes almost $40 \%$ of the energy is used in this zone. The implementation of the proposed solution should have a mass scale, and the regulations should recommend its use where possible. This solution may also be considered as a form of heat recovery from the exhaust air for which, for technical reasons, heat recovery could not be applied, e.g. due to: smell or pollution. Further analyses of the proposed solution with the use of air from ventilation systems with heat recovery and for air conditioners/heat pumps with variable capacity control are planned. Laboratory tests of the proposed solution are also planned.

The work was supported by The Faculty of Environmental Energy, Wroclaw University of Science and Technology, Poland. no. 0401/0055/18.

\section{References}

1. Directive 2010/31/EU of the European Parliament and of the Council of 19 May 2010 on the energy performance of buildings (Official Journal of the EU, 2010)

2. P. Kowalski, P. Szałański, E3S Web of Conferences 17, 00045 (2017)

3. Air conditioners - market and perspectives (in Polish), Rynek Instalacyjny 5, (2015)

4. Air-conditioning and ventilation market in Poland and the Silesia (in Polish), (Park Naukowo-Technologiczny Euro-Centrum, Katowice, 2014)

5. L. Grignon-Massé, P. Rivière, J. Adnot, Energy Policy 39, 2152-2164 (2011)

6. S. H. Lee, Y. Jeon, H. J. Chung, W. Cho, Y. Kim, Appl. Therm. Eng. 144, 362-370 (2018)

7. G. Ala, A. Orioli, A. Di Gangi, Energy and economic analysis of air-to-air heat pumps as an alternative to domestic gas boiler heating systems in the South of Italy, Energy (2019) (to be published)

8. M. Dongellinia, C. Naldia, G. L. Morinia, Energy Procedia 78, 1123 - 1128 (2015)

9. K. Piechurski, M. Szulgowska-Zgrzywa, J. Danielewicz, E3S Web of Conferences 44, 00139 (2018)

10. E. Dudkiewicz, N. Fidorów-Kaprawy, Energy 127, 198-208 (2017)

11. W. Cepiński, E3S Web of Conferences 17, 00012 (2017)

12. C. Baglivo, P. M. Congedo, Energy Procedia 126, 187-194 (2017)

13. A. Pełech, Wentylacja i klimatyzacja. Podstawy (Oficyna Wydawnicza Politechniki Wrocławskiej, Wrocław 2008)

14. Recknagel, Sprenger, Hőnmann, Schramek, Kompendium wiedzy: Ogrzewnictwo, Klimatyzacja, Ciepła woda, Chłodnictwo 2008/2009 (Omni-Scala, 2008) 